\title{
БЕЗГЛЮТЕНОВЫЕ КЕКСЫ С АМАРАНТОВОЙ МУКОЙ
}

\author{
Е. Ю. Егорова, Л. А. Козубаева
}

Статья посвящена вопросам разработки новых мучных кондитерских изделий для потребителей, придерживающихся аглютеновой диеты. Объектом исследований являлась рецептура кекса на основе традиционного безглютенового сырья - рисовой и кукурузной муки - с добавлением полуобезжиренной муки из семян амаранта. Амарантовую муку вводили в тесто в виде однородной смеси с кукурузной или рисовой мукой в пределах от 5,0 \% до 25,0 \% от общего количества муки, предусмотренного рецептурой. По результатам исследований общих закономерностей изменения основных органолептических и физикохимических показателей качества получаемых кексов авторами предложены оптимальные комбинации кукурузной и амарантовой; рисовой и амарантовой муки. Показано, что использование в качестве основы теста кукурузной и амарантовой муки в соотношении 10,012,5 \%: 90-87,5 \% или рисовой и амарантовой муки в соотношении 15,0-17,5\%: 85,0-82,5 \% позволяет получать мучные кондитерские изделия стандартного качества. По сравнению $c$ реализуемыми аналогами, в новых кексах улучшается соотношение основных пищевых веществ: снижается содержание простых углеводов, повышается содержание пищевых волокон, легкоусвояемых белков и эссенциальных жирных кислот.

Ключевые слова: челиакия, аглютеновая диета, мучные кондитерские изделия, кексы, кукурузная мука, рисовая мука, амарант, амарантовая мука, пищевая ценность, оценка качества.

Разработка и внедрение новых продуктов специализированного назначения, в том числе направленных на профилактику и лечение целиакии, и насыщение потребительского рынка такими продуктами отечественного производства сохраняют свой приоритет в реализации государственных программ в области здорового питания и развития пищевой и перерабатывающей промышленности PФ [1, 2].

Целиакией (от лат. coeliakia, греч. koilikos - кишечный, страдающий расстройством кишечника) называют хроническое системное заболевание, связанное с необратимым поражением тонкой кишки и сопровождающееся системными аутоиммунными проявлениями. Считается, что целиакия развивается в основном у генетически предрасположенных к этому людей, в результате употребления в пищу глютена. Однако кроме врожденной, целиакия может быть и приобретенной, спровоцированной избыточным потреблением высококлейковинного растительного белка, серьезным эмоциональным стрессом или продолжительным патологическим воздействием и т. д.

Недиагностированная целиакия, усугубленная длительной интоксикацией организма глютеном злаковых культур, является одной из причина вторичных иммунных нарушений - сахарного диабета 1 типа, задержки в пси- хическом развитии, язв и новообразований в полости рта и желудочно-кишечном тракте, эпилепсии и некоторых других [3-5].

В последние годы целиакия признается одним из наиболее часто встречающихся генетических заболеваний на планете, с распространённостью около $1 \%$ [3]. Вместе с тем, согласно прогнозам от начала 2017 года, более $5 \%$ мирового населения могут иметь генетическую предрасположенность к данному заболеванию [6].

Основным способом лечения целиакии является строгое пожизненное соблюдение аглютеновой диеты [7]. Содержание глютена - спирто-щелочерастворимых фракций белка злаковых культур (пшеница, рожь, ячмень, овес и некоторые другие) - в продуктах, разрешенных аглютеновой диетой (Gluten-Free Foods), не должно превышать 20 мг/кг.

Ассортимент безглютеновых продуктов в странах Европы и Америки включает готовый хлеб, пиццу, разнообразные мучные кондитерские (кексы, бисквиты, печенье и т. д.) и кулинарные (блинчики, оладьи) изделия, сухие смеси для их получения в домашних условиях, макаронные изделия. В России объем продаж безглютеновых продуктов оценивается примерно в $\$ 64 \mathrm{mлн.} \mathrm{[6],} \mathrm{но} \mathrm{ассор-}$ тимент таких продуктов несопоставимо узкий. Как следствие, реализуемые в России безглютеновые продукты - преимущественно, 


\section{БЕЗГЛЮТЕНОВЫЕ КЕКСЫ С АМАРАНТОВОЙ МУКОЙ}

зарубежных производителей: Glutano (Германия), Polenta, Dr. Schar, Reisbrot, Cerealvit, NUTRI FREE, Farmo (Италия), Gullon (Испания), Bezgluten и Balviten (Польша), и они существенно дороже традиционных продуктов с глютеном. Из отечественных известны три торговые марки: «Макмастер», «ВНИИК» и «Гранец», представленные в европейской части России и поставляющие безглютеновые продукты по всей России через интернетмагазины.

В качестве основных видов безглютеновой муки производители обычно используют кукурузную и рисовую, несколько реже гречневую. Возникающее при замене пшеничной муки ухудшение технологических свойств теста компенсируется включением в рецептуру крахмалов [5, 8-10]. Однако продукция на основе таких ингредиентов, особенно при использовании рисовой и кукурузной муки и крахмала, характеризуется невысокой пищевой ценностью и повышенной скоростью очерствения, поэтому при разработке новых продуктов более целесообразным считается комбинирование двух-трех видов муки, не содержащей глютен [11].

Таким образом, узкий ассортимент отечественных продуктов для больных целиакией, высокие цены продуктов от зарубежных производителей и, как правило, низкая пищевая ценность реализуемых безглютеновых продуктов определяют целесообразность разработки новых хлебобулочных и мучных кондитерских изделий, адаптированных для безглютенового питания.

Целью данной работы являлось определение оптимальной дозировки муки из семян амаранта для получения безглютеновых кексов на основе традиционного безглютенового сырья - рисовой и кукурузной муки.

Мука из семян амаранта (Amaránthus) ценится за высокое содержание ряда незаменимых в сбалансированном питании компонентов, прежде всего - легкоусвояемого белка, не включающего глютеновую фракцию [12-14]. От рисовой и кукурузной муки полуобезжиренная мука из семян амаранта (рисунок 1) отличается значительно более низким содержанием усвояемых углеводов (таблица 1) и наличием сложных уплотненных ассоциатов белков и мелкозернистого крахмала, обусловливающих потенциально высокую водопоглотительную способность амарантовой муки [15]

Bce выше сказанное определяет соответствие амарантовой муки цели исследования и требованиям кондитерского производства.

ПОЛЗУНОВСКИЙ ВЕСТНИК № 12018

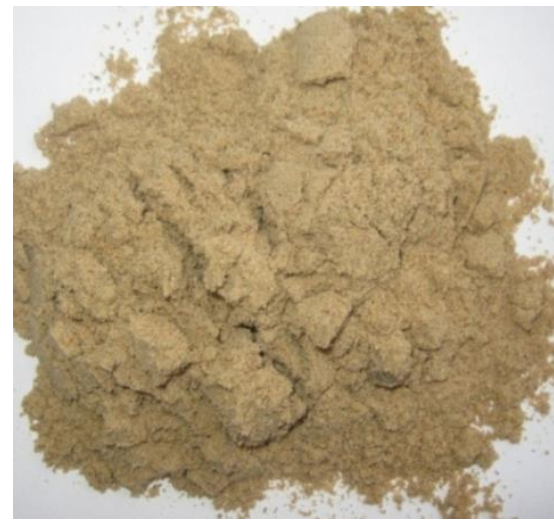

Рисунок 1 - Амарантовая мука

В работе использовали рисовую и кукурузную муку ООО ТД «ЭНДАКСИ» (г. Владимир) и полуобезжиренную амарантовую муку производства ООО «Специалист» (г. Бийск).

За основу при отработке рецептур безглютеновых кексов взята фрормула патента РФ 2538400 [16]. Амарантовую муку вводили в тесто в виде однородной смеси с кукурузной или рисовой мукой в количестве от 5,0\% до $25,0 \%$ от массы основного вида муки, с «шагом» варьирования 2,5 \%. Кексы выпекали в одноразовых бумажных формах при температуре $175 \pm 2{ }^{\circ} \mathrm{C}$ в течение $25-30$ минут. При повышении температуры выпечки поверхность кекса подгорала, а центр мякиша оставался непропеченным [17].

Для каждого варианта рецептуры приготовление теста, выпечку и анализ показателей качества кексов проводили в 3-4-кратной повторности. Оценку качества кексов проводили в соответствие с ГОСТ 15052-2014, для продукции на химических разрыхлителях.

Согласно результатам дегустационной оценки, кексы на основе кукурузной муки сохраняли равномерную мелкую пористость, разрыхленную структуру, не имели пустот и признаков непромеса при замене на амарантовую муку до 20,0 \% от рецептурного количества муки, кексы на основе рисовой муки во всем изученном интервале дозировки амарантовой муки (до 25,0 \% включительно). Вследствие различий в химическом составе рисовой и кукурузной муки, кексы на основе кукурузной муки «поднимались» хуже.

Кексы из кукурузной муки имели светложелтый цвет, кексы из рисовой муки - светлокремовый. По мере увеличения дозировки амарантовой муки - от 15,0 \% и выше - цвет кексов приобретал более темный оттенок, пористость мякиша становилась менее развитой и уплотненной, поверхность кексов более гладкой, а подсушенный корковый слой - более толстым (рисунок 2). Начиная с дози- 
ровки амарантовой муки 15,0-17,5 \% кексы приобретали её характерный привкус и слабо выраженный хруст частиц оболочек семян амаранта. Вкус кукурузной и рисовой муки с увеличением дозировки амарантовой муки постепенно ослабевал, в мякише изделий становились заметны темные включения частиц амарантовой муки.

Согласно результатам фризикохимических испытаний (таблица 2), увеличение в тесте доли амарантовой муки сопровождалось почти линейным снижением влажности и щелочности кексов. При этом кексы на основе рисовой муки почти по всем вариантам исследования имели более высокую влажность, вероятно, изначально обусловленную более высоким содержанием крахмала в рисовой муке по сравнению с кукурузной.

Очевидно, что наблюдаемая динамика оцениваемых фризико-химических показателей связана с более низкой влажностью ама- рантовой муки и наличием в её составе остаточного количества масла, свободные жирные кислоты которого частично компенсируют щелочную реакцию предусмотренного рецептурой разрыхлителя.

С повышением дозировки амарантовой муки изделия становились более плотными, что обусловлено ухудшением разрыхленности мякиша изделий. Значение этого показателя можно считать превысившим норматив при замене на амарантовую от 20 \% рисовой и более 25 \% кукурузной муки.

Анализ зольности кексов, выполненный ускоренным методом с использованием спиртового раствора уксуснокислого магния, показал незначительное увеличение содержания в кексах нерастворимой золы, не превышающее норматива, установленного ГОСТ 15052-2014 (не более 0,1\%).

Таблица 1 - Общая характеристика рисовой, кукурузной и амарантовой муки

\begin{tabular}{|l|c|c|c|}
\hline \multirow{2}{*}{$\begin{array}{c}\text { Наименование } \\
\text { компонента }\end{array}$} & \multicolumn{2}{|c|}{ Содержание компонента, в 100 г муки } \\
\cline { 2 - 4 } & рисовой & кукурузной & амарантовой [18] \\
\hline Вода, г & 11,9 & 14,0 & 12,1 \\
\hline Белки, г & 6,0 & 7,2 & 41,4 \\
\hline Жиры, г & 1,4 & 1,5 & 3,7 \\
\hline Углеводы, г & 80,1 & 72,1 & 3,4 \\
\hline Пищевые волокна, г & 2,4 & 4,4 & \\
\hline
\end{tabular}

a)

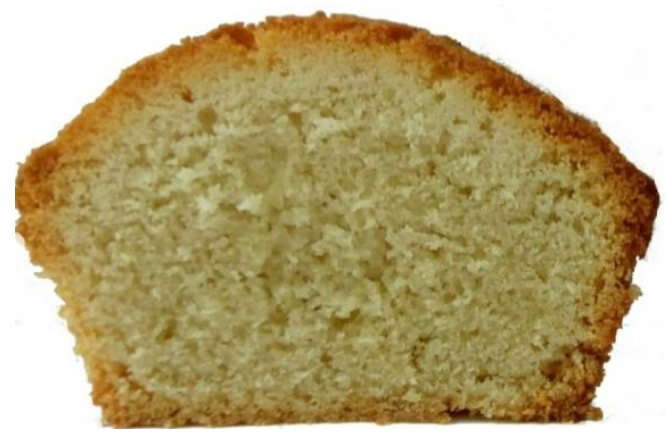

B)

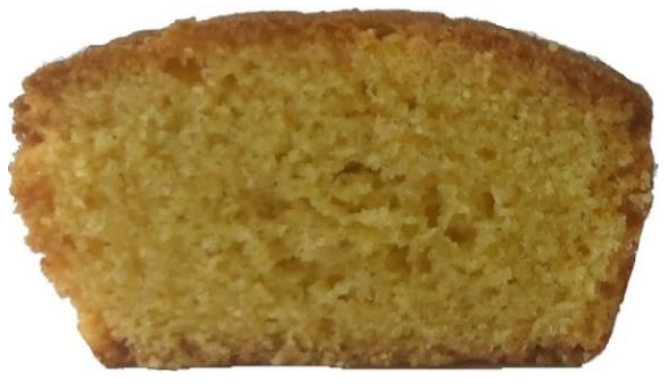

б)

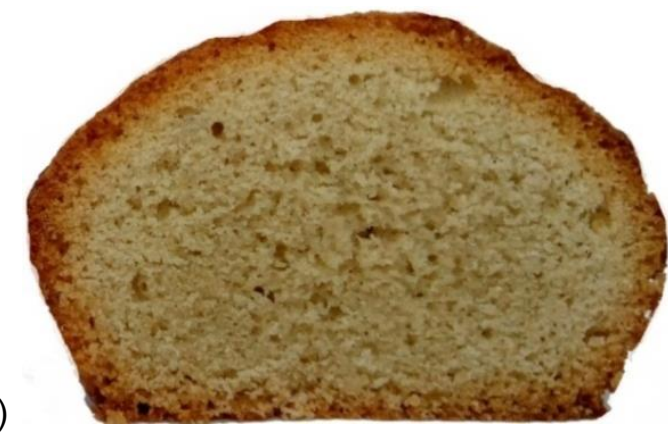

г)

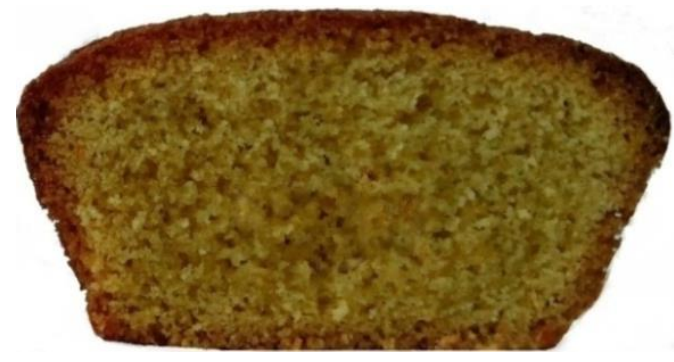

Рисунок 2 - Вид выпеченных изделий, в разрезе:

а) кекс из рисовой муки, б) кекс из смеси рисовой и амарантовой муки в соотношении 75,0 \%: 25,0\%, в) кекс из кукурузной муки,

г) кекс из смеси кукурузной и амарантовой муки в соотношении 85,0 \%: 15,0\% 


\section{БЕЗГЛЮТЕНОВЫЕ КЕКСЫ С АМАРАНТОВОЙ МУКОЙ}

Таблица 2 - Влияние амарантовой муки на фризико-химические показатели качества кексов

\begin{tabular}{|c|c|c|c|c|c|c|}
\hline Дозировка & \multicolumn{5}{|c|}{ Наименование показателя } \\
\cline { 2 - 2 } амарантовой \\
муки, \%
\end{tabular}

По результатам проведенных исследований оптимальной комбинацией кукурузной и амарантовой муки для разработки новых рецептур безглютеновых кексов можно считать 10,0-12,5\%: 90-87,5\%, рисовой и амарантовой муки - 15,0-17,5\%: 85,0-82,5\%. Использование в качестве основы теста для кексов этих видов муки в предложенных соотношениях позволяет получать продукцию стандартного качества.

Расчет пищевой ценности выпеченных изделий показывает, что, по сравнению с реализуемыми аналогами, в новых кексах улучшается соотношение основных пищевых веществ: снижается доля простых углеводов (за счет уменьшения содержания крахмала кукурузной или рисовой муки), повышается содержание пищевых волокон, легкоусвояемых белков и эссенциальных жирных кислот.

\section{СПИСОК ЛИТЕРАТУРЫ}

1. Резниченко, И.Ю. Теоретические аспекты разработки и классификации кондитерских изделий специализированного назначения / И.Ю. Рез- ниченко, Е.Ю. Егорова // Техника и технология пищевых производств. - 2013. - № 3. - С. 133-138.

2. Резниченко, И.Ю. Совершенствование ассортимента кондитерских изделий специализированного назначения / И.Ю. Резниченко, Н.Н. Зоркина, Е.Ю. Егорова // Ползуновский вестник. 2016. - № 2. - C. 4-7.

3. Копишинская, С.В. Современные представления о целиакии / С.В. Копишинская // Казанский медицинский журнал. - 2016. - Т. 97. - № 1. С. 101-107.

4. Михалик, Д.С. Целиакия: болезнь и образ жизни / Д.С. Михалик, Г.В. Жуков, Л.И. Николаенкова, И.С. Козлова, Т.А. Богданова // Земский врач. - 2012. - № 4. - С. 35-38.

5. Резниченко, И.Ю. Современные требования к качеству и безопасности безглютеновой продукции в Великобритании. Информационное обеспечение потребителей / И.Ю. Резниченко, Ю.А. Алешина // Ползуновский вестник. - 2011. № 3/2. - С. 219-222.

6. Рынок безглютеновой продукции // Пищевая индустрия. - 2017. - № 1 (31). - С. 8-10.

7. Крумс, Л.М. Лечение и профилактика глютенчувствительной целиакии / Л.М. Крумс, А.И. Парфенов, Е.А. Сабельникова, Р.Б. Гудкова, Н.Н. Воробьева // Экспериментальная и клиниче- 


\section{Е. Ю. ЕГОРОВА, Л. А. КОЗУБАЕВА}

ская гастроэнтерология. - 2011. - № 2. - С. 86-92.

8. Аширова, Н.Н. Разработка новых рецептур и технологий безглютеновых кулинарных изделий на основе рисовой муки / Н.Н. Аширова // Научное обозрение. - 2014. - № 9-1. - С. 17-19.

9. Шнейдер, Д.В. Безглютеновые смеси для выпечки из кукурузной, рисовой и гречневой муки / Д.В. Шнейдер, Е.И. Крылова // Пищевая промышленность. - 2012. - № 8. - С. 63-65.

10. Дворядкина, Е.Б. Особенности рынка полуфабрикатов для производства мучных кулинарных изделий / Е.Б. Дворядкина, О.В. Чугунова, В.М. Тиунов // Технологии пищевой и перерабатывающей промышленности АПК - продукты здорового питания. - 2016. - № 6 (14). - С. 32-41.

11. Домбровская, Я.П. Обогащение сухих смесей для производства безглютеновых кексов / Я.П. Домбровская, А.В. Сурмина, Д.А. Закалюжный // Вестник ВГУИТ. - 2017. - Т. 79. - № 1 (71). C. 130-133.

12. Ogrodowska, D. Amaranth seeds and products - the source of bioactive compounds / D. Ogrodowska, R. Zadernowski, S. Czaplicki, D. Derewiaka, B. Wronowska // Polish Journal of Food and Nutrition Sciences. - 2014. - № 64 (3). - C. 165170.

13. Звягин, А.А. Потенциальные возможности амарантовой муки как безглютенового продукта / А.А. Звягин, И.А. Бавыкина, И.М. Жаркова, Л.А. Мирошниченко // Вопросы детской диетологии. - 2015. - Т. 13. - № 2. - С. 46-51.

14. Матвеева, И.В. Амарантовая мука в качестве сырья для производства безглютеновых мучных кондитерских изделий / И.В. Матвеева, В.В. Нестеренко // Хлебопродукты. - 2012. - № 11. - C. 48-50.

15. Шмалько, Н.А. Особенности микрострук- туры и химического состава продуктов переработки зерна амаранта / Н.А. Шмалько, И.А. Чалова, Н.А. Моисеенко, Н.Л. Ромашко // Техника и технология пищевых производств. - 2011. - № 1. C. 57-63.

16. Пат. РФ № 2538400, A21D 13/08. Способ производства безглютенового мучного кондитерского изделия / И.М. Жаркова, М.В. Хромых (Россия). - № 2012121180/13; заяв. 29.11.2012; опубл. 10.01.2015, Бюл. № 1. - 8 с.

17. Кравец, О.В. Разработка рецептуры безглютенового кекса / О.В. Кравец, Е.Ю. Егорова // Горизонты образования. - 2017. - Вып. 19, секция «Пищевая промышленность». - С. 54-57.

18. Смирнов, С.О. Разработка технологии разделения зерна амаранта на анатомические части и получения из них нативных продуктов: дисс. ... канд. техн. наук: 05.18.01. - М., 2006. $215 \mathrm{c}$

Егорова Елена Юрьевна, д.т.н., профессор кафердры технологии хранения и переработки зерна ФГБОУВО «Алтайский государственный технический университет им. И.И. Ползунова», 656038, е. Барнаул, ул. Ленина, 46, e-mail: egorovaeyu@mail.ru, тел.: (3852) 29-07-55.

Козубаева Людмила Алексеевна, к.т.н., доцент кафредры технологии хранения и переработки зерна ФГБОУ ВО «Алтайский государственный технический университет им. И.И. Ползунова», 656038, г. Барнаул, ул. Ленина, 46, e-mail: cosubaeva@mail.ru, тел.: (3852) 29-07-55. 